\title{
Análise de pacientes com leucemia mieloide crônica com resistência primária ou secundária ao mesilato de imatinibe
}

\author{
Analysis of chronic myelogenous leukemia patients with primary or secondary resistance to \\ imatinib mesylate
}

Rita de Cássia S. Alves

\section{Introdução}

A leucemia mieloide crônica é uma doença mieloproliferativa clonal resultante da transformação neoplásica associada a uma lesão genética específica, isto é, a translocação balanceada, t(9;22) (q34; q11), formando 9q+ e o pequeno 22q-, conhecido como Philadelphia (Ph) (Nowel, Hungerford, 1960). Como resultado desta translocação na
O mesilato de imatinibe, como terapia alvo, se revelou altamente eficiente na leucemia mielóide crônica. Um desafio é a resistência primária ou secundária, principalmente nas fases avançadas da doença. Na secundária, as mutações pontuais no domínio quinase $A B L$ são o mecanismo mais frequente. Estudou-se no período de outubro de 2000 a dezembro de 2005, 112 pacientes no Serviço de Hematologia e Hemoterapia da Santa Casa de São Paulo. O objetivo foi caracterizar o perfil dos resistentes e pesquisar a presença de mutação. Encontrou-se maior porcentagem de resistentes nas fases mais avançadas. Foram fatores de risco para resistência na fase crônica o número de plaquetas superior a $450.000 / \mathrm{mm}^{3}$ pré-imatinibe ou plaquetas inferior a 50.000/ $\mathrm{mm}^{3}$ durante o tratamento. A taxa de resposta hematológica completa e o tempo para obtenção foram semelhantes entre os resistentes e não resistentes. Observou-se menor sobrevida global nos resistentes. Destacaram-se dez pacientes resistentes com resposta citogenética completa pós 12 meses, "responsivos tardios", cuja freqüência de resposta hematológica e citogenética foi semelhante aos não resistentes (100\%). A sobrevida livre de progressão foi similar até aos 40 meses e a sobrevida global até aos 70 meses. A sobrevida global e as respostas foram superiores aos demais resistentes. Referente à pesquisa de mutação, analisou-se 22 resistentes, dos quais oito apresentaram mutação (36,4\%). Caracterizouse maior risco para a condição de mutação, a presença de blastos no sangue periférico ao diagnóstico nos pacientes em fase crônica. Rev. Bras. Hematol. Hemoter. 2009; 31(3):166-177.

Palavras-chave: Leucemia mieloide crônica; inibidor de proteína tirosina-quinase; mesilato de imatinibe; resistência; mutação.

${ }^{1}$ Médica Assistente da Santa Casa de São Paulo - São Paulo-SP.

Santa Casa de São Paulo (USP) - São Paulo-SP.

Correspondência: Rita de Cássia Silva Alves

Hemocentro da Santa Casa de São Paulo

Rua Marquês de Itu, $579-2^{\circ}$ andar

01223-001 - São Paulo-SP - Brasil

Tel: (55 11) 2176-7000 ramal: 5964

E-mail: bs.citogenetica@santacasasp.org.br

Doi:10.1590/S1516-84842009005000053 
proporcionaram mudanças radicais no tratamento da doença e um novo paradigma na terapia do câncer. ${ }^{1}$

A partir de 1990, vários pesquisadores iniciaram projetos para a síntese de moléculas, capazes de inibir a atividade de tirosina quinase da proteína BCR-ABL, através de competição na ocupação no sítio de ligação de adenosina trifosfato (ATP), no domínio quinase BCR-ABL. Destacou-se na classe dos compostos conhecidos como 2-fenilaminopirimidinas, STI-571 (mesilato de imatinibe), o qual apresenta um efeito inibidor específico sobre três tirosinas quinases: ABL (BCRABL, v-ABL, c-ABL), PDGF (fator de crescimento derivado de plaquetas), c-Kit e a tirosina quinase ABL. Através desta característica promove uma atividade antiproliferativa em linhagens celulares que expressam proteína ABL ativada e levam à morte celular por apoptose. ${ }^{1}$

O mesilato de imatinibe revelou-se um excepcional agente terapêutico particularmente para os pacientes em fase crônica, porém com a experiência observou-se que uma minoria de pacientes em fase crônica e uma alta proporção de pacientes em fase avançadas evoluem com refratariedade ao tratamento (resistência primária) ou com a perda da sensibilidade ao longo do tempo e recaída (resistência secundária). ${ }^{2}$

A resistência ao imatinibe tem sido associada com múltiplos mecanismos heterogêneos, porém há um menor conhecimento dos processos moleculares responsáveis pela refratariedade. Coloca-se que muitos mecanismos que atuam independente da atividade de BCR-ABL são responsáveis pela resistência primária, ${ }^{3}$ como a ativação de PI3K/AKt, / Lyn e Src. ${ }^{2}$

Em relação à resistência secundária, é conhecido que a maioria dos casos se deve à reativação de BCR-ABL. As mutações no domínio quinase ABL representam o mecanismo mais comum, sendo responsável por $50 \%$ a $90 \%$ dos casos. Atuam impedindo a ligação do imatinibe ao BCR-ABL ou induzem a uma transição da conformação inativa para a ativa, na qual o fármaco é incapaz de se ligar. Aproximadamente em $10 \%$ dos casos há superprodução de BCR-ABL, mais comumente por amplificação gênica ou aquisição de cromossomos Ph adicionais. ${ }^{3}$

Tendo em vista a importância que o desenvolvimento da resistência representa no tratamento, principalmente nas fases mais avançadas, decidiu-se analisar pacientes resistentes, em uso de mesilato de imatinibe, objetivando-se determinar fatores de risco para estabelecimento dessa condição e identificou-se, entre os mecanismos responsáveis pelo processo, a presença de mutação no domínio quinase ABL.

\section{Casuística e Método}

No Serviço de Hematologia e Hemoterapia da Santa Casa de São Paulo, no período de outubro de 2000 e dezembro de 2005, foram acompanhados 112 pacientes com leucemia mieloide crônica em fase crônica, fase acelerada ou crise blástica. Os primeiros 61 pacientes fizeram parte do estudo de acesso expandido fase II - STI571. Com o término desse estudo, em 28 de fevereiro de 2002, os demais foram admitidos com os mesmos critérios.

O estudo foi submetido e aprovado pelo Comitê de Ética em Pesquisa em seres humanos e foi obtido o termo de consentimento livre e esclarecido dos pacientes ao estudo de mutação do domínio quinase ABL. Foram considerados como critério de inclusão, pacientes com leucemia mieloide crônica Ph positivo, em fase crônica resistentes ou intolerantes ao IFN- $\alpha$, em fase acelerada ou crise blástica.

Resistência ao IFN- $\alpha$ definiu-se como ausência de resposta hematológica completa com uso no mínimo por três meses e cariótipo com $65 \%$ ou mais células Ph positivo após um ano de tratamento. Intolerância ao IFN- $\alpha$ definiu-se como desenvolvimento de toxicidade não hematológica grau 3 ou 4 .

Os critérios de exclusão foram: gestação; estratificação de performance $\geq 3$ (ECOG - Eastern Cooperative Oncology Group Performance States Scale); transaminases, bilirrubina total sérica e creatinina duas vezes o limite superior de normalidade; falência cardíaca classes III e IV (classificação: New York Heart Association) e pacientes que receberam outros agentes quimioterápicos dentro de duas semanas do começo do estudo, exceto hidroxiureia.

Os critérios para definição da fase crônica foram: porcentagem inferior a $10 \%$ de blastos, $20 \%$ de basófilos e $30 \%$ de blastos mais promielócitos em sangue periférico ou medula óssea; contagem de plaquetas igual ou superior a $100.000 / \mathrm{mm}^{3}$. Fase crônica inicial e tardia definiu-se segundo o intervalo entre o diagnóstico e o início da terapêutica, ou seja, inferior ou superior a doze meses, respectivamente. Para fase acelerada: porcentagem de blastos superior a 15\% e inferior a 30\% em sangue periférico ou medula óssea, ou blastos mais promielócitos superior a 30\%, ou basófilos superior a $20 \%$ no sangue periférico ou medula óssea, ou contagem de plaquetas inferior a $100.000 / \mathrm{mm}^{3}$, não relacionada à terapia, ou esplenomegalia progressiva com mais de $10 \mathrm{~cm}$ do rebordo costal esquerdo ou evolução clonal. Para crise blástica: porcentagem de blastos superior a 30\% em sangue periférico ou medula óssea ou doença extramedular, exceto linfonodo, baço ou fígado.

Em relação à terapia, os pacientes em fase crônica receberam 400 mg e 600 mg na fase acelerada e crise blástica.

Os pacientes foram classificados para resistência ao mesilato de imatinibe, segundo critérios hematológicos e citogenético, como resistentes primários, ou seja, droga é ineficaz no início tratamento, ou resistentes secundário, isto é, com perda da eficácia da droga depois da resposta inicial à terapia.

Considerou-se resistência hematológica, na fase crônica a falta ou perda da normalização das contagens celulares do sangue, com diferencial normal e do tamanho o baço. A resposta hematológica completa deveria ser obtida até 12 semanas. Nas fases avançadas foi determinado como falta do retorno à fase crônica ou recaída hematológica após res- 
posta inicial. Quanto a resistência citogenética considerouse como falta ou perda de resposta citogenética parcial $(=35 \%$ de metáfases $\mathrm{Ph}$ positiva) em seis meses ou da completa ( $0 \%$ de metáfases $\mathrm{Ph}$ positivo) em 12 meses.

Os eventos considerados para definição da sobrevida livre de progressão foram: perda da resposta hematológica completa ou citogenética completa, progressão para fase acelerada ou crise blástica e óbito.

Considerou-se responsivo tardio o paciente em fase crônica e com resistência citogenética, que obtém resposta citogenética completa após 12 meses (Iacobucci et al, 2006).

No Laboratório de Citogenética da Santa Casa de São Paulo, foi realizado o estudo citogenético convencional em medula óssea, através da técnica da Banda G. A análise foi realizada em 20 metáfases segundo as normas do Sistema Internacional de Nomenclatura de Citogenética Humana (ISCN - Mitelman, 1995), no sistema automatizado de cariotipagem.

A análise molecular, realizada no laboratório de biologia tumoral do Hospital das Clínicas da FMUSP, compreendeu inicialmente a extração de RNA, a partir de $20 \mathrm{ml}$ de sangue periférico colhido em EDTA, pela técnica Trizol/Clorofórmio. A partir do DNA complementar (cDNA) realizamos primeiramente um PCR qualitativo para definição de quebra em BCR-ABL b2a2(342pb) ou b3a2 (417pb). A PCR em tempo real ou PCR quantitativo QPCR permitiu a determinação da quantidade do produto amplificado. Para cada gene estudado foi preparada uma reação específica em diferentes exons do gene b2a2 com 96pb: primer foward: 5'atc cgt gga gct gca gat g-3'; Reverse primer: 5'cgc tga agg cgt tct tcc tt; Sonda: 5 'cca act cgt gtg tga aac tcc aga ctg tcc; gene b3a2 com 74pb: Forward primer: 5'ggg ctc tat ggg ttt ctg aat g; Reverse primer: 5'cgc tga agg gct ttt gaa ct; Sonda: 5'cat cgt cca ctc agc cac tgg att taa gc; gene BCR com 67pb: Forward primer: 5 'cct tcg acg tca ata aca agg at; Reverse primer: 5 'cct gcg atg cgc ttc ac, Sonda: 5 'tcc atc tcg ctc atc atc acc gac a ,equipamento Rotor-Gene RG 3000 (Corbett Research), com a tecnologia TaqMan(Applied Biosystems).

Para detecção de mutações no domínio quinase do gene ABL, utilizou-se a técnica RT-PCR "seminested", e utilizamos o primer senso localizado no exon b2 do gene BCR: 5'TGA CCAACT CGT GTC TGAAAC TC 3' e o antissenso na região de quinase do gene ABL: 5'TCC ACT TCG TCT GAG ATA CTG GAT T 3', posteriormente foram amplificados novamente, mas utilizamos o primer senso da região quinase do gene ABL: 5'CGC AAC AAG CCC ACTT 3'. A reação foi realizada em termociclador PTC 200(MJ Research, USA), e o material amplificado foi sequenciado com a técnica do Big Dye Versão 3.1 em um sequenciador automático 3130 (Applied Biosystem, USA).

\section{Estatística}

Para as variáveis contínuas, as médias foram comparadas utilizando um modelo de análise de variância (ANOVA).
Utilizou-se o teste Qui quadrado de Pearson $\left(\chi^{2}\right)$ ou teste exato de Fisher para as variáveis categóricas, considerandose como significantes os valores de (p) menores do que 0,05. Modelos de regressão logística foram utilizados para avaliação da associação entre resistência e variáveis, selecionadas com base na análise univariada e pela seleção de variáveis pelo método Stepwise forward.

Curvas de sobrevida foram calculados pelo método Kaplan Meier (K-M) e a comparação entre as duas curvas pelo teste log-rank ou teste de Breslow. O programa utilizado foi STATA versão 8 e SPSS versão 13.0.

\section{Resultados}

\section{Fase Crônica}

Constituiu-se de setenta pacientes com idade mediana igual a 42,3 meses (19,2-71,8 meses) com seguimento mediano igual a 43,5 meses (5,7-73,3). Destes pacientes, 67 (95,7\%) fizeram uso do interferon- $\alpha$ e desenvolveram intolerância (22,4\%) ou resistência hematológica ou citogenética (58,2\%) ou recidiva hematológica ou citogenética (19,4\%). Ao final da análise 48 pacientes $(68,6 \%)$ permaneciam sob tratamento com imatinibe. As características clínicas podem ser observadas na Tabela 1.

Houve obtenção de resposta hematológica completa em $98,6 \%$ e resposta citogenética maior e completa em $61,4 \%$ e $55,7 \%$, respectivamente. A sobrevida livre de progressão foi igual a 67,6\% em 60 meses (Figura 1).

Segundo os critérios de resistência hematológica e citogenética, caracterizaram-se 45 pacientes $(64,3 \%)$ resistentes e 25 (35,7\%) não resistentes. Identificou-se um paciente com resistência primária hematológica (1,4\%) e 34 com citogenética primária (49,3\%).

Referente à resistência secundária houve uma variação de 17,3\% a 32,4\%, entre 18 e 60 meses, respectivamente.

Caracterizaram-se dez pacientes com resistência secundária, dos quais três apresentaram perda da resposta citogenética completa e sete evoluíram para fases mais avançadas da doença.

Considerando-se os dez pacientes em fase crônica inicial, houve um caso com resistência secundária (10\%) e, na tardia, 35 com resistência primária e nove em resistência secundária (73,3\%), como pode ser observado na Figura 3. Caracterizou-se uma diferença estatística significante.

A resposta molecular, através de RTQ-PCR, foi estudada em 26 (57,8\%) pacientes resistentes e nos 25 pacientes não resistentes, pois esta análise iniciou-se em outubro de 2005.

\section{Fase Acelerada}

Treze pacientes em fase acelerada, com uma idade mediana igual a 48,9 anos (19 - 76,7) e um tempo mediano de seguimento igual a 14 meses. Destes, dez (76,9\%) fizeram uso de IFN- $\alpha$ dos quais seis (60\%), desenvolveram intolerância e os demais resistência hematológica ou citogenética. As 
características clínicas podem ser observadas na Tabela 1.

Sete pacientes $(53,95)$ obtiveram resposta hematológica completa. A avaliação da resposta citogenética foi prejudicada por exames inconclusivos ou não realizados, sendo possível caracterizar ausência de resposta citogenética maior em quatro pacientes e presença de resposta citogenética completa em um paciente.

Todos os pacientes foram definidos como resistentes (100\%), dos quais classificaram-se oito (61,5\%) com resistência primária, sendo seis hematológica $(46,1 \%)$ e dois citogenética $(15,4 \%)$.

\section{Crise Blástica}

Vinte e nove pacientes em crise blástica, com uma idade mediana igual a 48,2 anos $(23,1-76,6)$ com tempo mediano de seguimento igual a 6,7 meses $(0,2$ - 50,3). Dezoito pacientes $(62,1 \%)$ fizeram uso do IFN- $\alpha$, dos quais 14 (77,3\%) evoluíram com intolerância e 4 (22,2\%) com resistência hematológica ou citogenética. As características clínicas podem ser observadas na Tabela 1.

A resposta hematológica completa foi obtida em nove pacientes (31\%). A avaliação citogenética foi prejudicada por resultados inconclusivos e não avaliáveis, mas dois pacien-

\begin{tabular}{|c|c|c|c|}
\hline & $\begin{array}{l}\text { Fase } \\
\text { Crônica }\end{array}$ & $\begin{array}{c}\text { Fase } \\
\text { Acelerada }\end{array}$ & $\begin{array}{l}\text { Crise } \\
\text { Blástica }\end{array}$ \\
\hline dade & $\begin{array}{c}42,3 \\
(19,2-71,8)\end{array}$ & $\begin{array}{c}48,9 \\
(19-76,7)\end{array}$ & $\begin{array}{c}48,2 \\
(23,1-76,6)\end{array}$ \\
\hline $\begin{array}{l}\text { Tempo de diagnóstico } \\
\text { até início do imatinibe }\end{array}$ & $\begin{array}{c}26,8 \\
(0,9-129,5)\end{array}$ & $\begin{array}{c}45,5 \\
(3,9-218,7)\end{array}$ & $\begin{array}{c}47,1 \\
(1,4-309,8)\end{array}$ \\
\hline $\begin{array}{l}\text { Tempo de seguimento } \\
\text { com imatinibe }\end{array}$ & $\begin{array}{c}43,5 \\
(5,7-73,3)\end{array}$ & $\begin{array}{c}14 \\
(0,7-78,2)\end{array}$ & $\begin{array}{c}6,7 \\
(0,2-50,3)\end{array}$ \\
\hline $\begin{array}{l}\text { Tempo de uso do } \\
\text { IFN- } \alpha \text { (meses) }\end{array}$ & $\begin{array}{c}9,2 \\
(0,1-113,3)\end{array}$ & $\begin{array}{c}7,9 \\
(1,2-64,7)\end{array}$ & $\begin{array}{c}6,1 \\
(0,9-44,2)\end{array}$ \\
\hline $\begin{array}{l}\text { Sexo } \\
\text { Masculino } \\
\text { Feminino }\end{array}$ & $\begin{array}{l}36(51,4) \\
34(48,6)\end{array}$ & $\begin{array}{l}9(69,2) \\
4(30,8)\end{array}$ & $\begin{array}{l}14(48,3) \\
15(51,7)\end{array}$ \\
\hline $\begin{array}{l}\text { Uso do IFN- } \alpha \\
\text { Sim } \\
\text { Não }\end{array}$ & $\begin{array}{c}3(4,3) \\
67(95,7)\end{array}$ & $\begin{array}{c}10(76,9) \\
3(23,1)\end{array}$ & $\begin{array}{l}18(62,1) \\
11(37,9)\end{array}$ \\
\hline $\begin{array}{l}\text { Status em relação do IFN- } \alpha \\
\text { Intolerância } \\
\text { Resistência Citogenética } \\
\text { Resistência Hematológica } \\
\text { Recidiva Citogenética } \\
\text { Recidiva Hematológica }\end{array}$ & $\begin{array}{c}15(22,4) \\
23(34,3) \\
16(23,9) \\
4(6,0) \\
9(13,4)\end{array}$ & $\begin{array}{l}2(20) \\
1(10) \\
5(50) \\
0 \\
2(20)\end{array}$ & $\begin{array}{c}14(77,8) \\
2(11,1) \\
2(11,1) \\
0 \\
0\end{array}$ \\
\hline $\begin{array}{l}\text { Status atual } \\
\text { Saída estudo } \\
\text { Fim de seguimento } \\
\text { Óbito pela doença } \\
\text { Óbito por outra causa } \\
\text { Vivos em seguimento }\end{array}$ & $\begin{array}{c}7(10) \\
2(2,9) \\
10(14,3) \\
3(4,2) \\
48(68,6)\end{array}$ & $\begin{array}{c}0 \\
2(15,4) \\
10(76,9) \\
0 \\
1(7,7)\end{array}$ & $\begin{array}{c}1(3,4) \\
7(24,3) \\
21(72,4) \\
0 \\
0\end{array}$ \\
\hline
\end{tabular}

*: Números de pacientes com uso do IFN- $\alpha$ tes atingiram resposta citogenética completa, aos 11 e 16 meses respectivamente.

Vinte e oito pacientes (96,5\%) foram classificados como resistentes, dos quais 20 com resistência hematológica primária (69\%) e um paciente com citogenética primária. Entre os sete pacientes restantes, foi possível definir um caso como resistência hematológica secundária e os demais não tiveram estudo citogenético conclusivo, mas apresentam perda da resposta hematológica.

Como pode ser visto na Figura 3, houve um aumento crescente da porcentagem da resistência da fase crônica inicial às fases avançadas (10\% a 100\%).

Realizada análise univariada e multivariada referente a variáveis clínicas e laboratoriais entre os 45 pacientes resistentes e 25 não resistentes em fase crônica.

A Tabela 2 sumariza o estudo univariado dos fatores de risco para desenvolvimento da resistência, onde se observa associação estatística significante com o número de plaquetas pré-imatinibe $\left(>450.000 / \mathrm{mm}^{3}\right)$ e com uma contagem inferior a $50.000 / \mathrm{mm}^{3}$ durante o tratamento. Os resultados do estudo multivariado demonstraram que a chance de ser resistente foi igual a 4,7 vezes para os pacientes com número de plaquetas superior a $450.000 / \mathrm{mm}^{3}$ pré-imatinibe ou 5,6 vezes para aqueles que apresentaram número inferior a $50.000 / \mathrm{mm}^{3}$ durante o tratamento (Tabela 3).

Respostas hematológica, citogenética e sobrevida global entre resistentes e não resistentes

Não houve diferença estatística entre a obtenção de resposta hematológica completa entre não resistentes (100\%) e resistentes (97,8\%) e o tempo para sua obtenção, como pode ser visto nas Tabelas 4 e 5. Mas como é apontado na Tabela 4, houve uma diferença na resposta citogenética completa.

Na Figura 4, observa-se que 14 pacientes resistentes obtêm a resposta citogenética completa em um tempo mediano igual a 57,5 meses. Dez pacientes a adquiriram após 12 meses (responsivos tardios), em um tempo mediano igual a 29,2 meses, como é demonstrado na Figura 5.

Não houve diferença entre pacientes resistentes e não resistentes quanto à idade ao iniciar o imatinibe, tempo de uso do interferon- $\alpha$ e evolução clonal (Tabelas 4 e 5).

A sobrevida global dos 45 pacientes resistentes foi significantemente menor em relação aos 25 pacientes não resistentes, como observado na Figura 6. Contudo, os pacientes resistentes com resposta citogenética completa pós 12 meses apresentaram, em relação aos não resistentes, sobrevida global semelhante até os 70 meses e sobrevida livre de progressão até os 40 meses, como é observado nas Figuras 7 e 8 respectivamente. 
Pesquisa de mutação no domínio quinase $A B L$

Identificaram-se oito pacientes (36,4\%) entre 22 pacientes resistentes analisados para a pesquisa de mutação pontual no domínio quinase ABL, em um tempo mediano igual a 42 meses (18 - 63) após o início do tratamento com imatinibe.

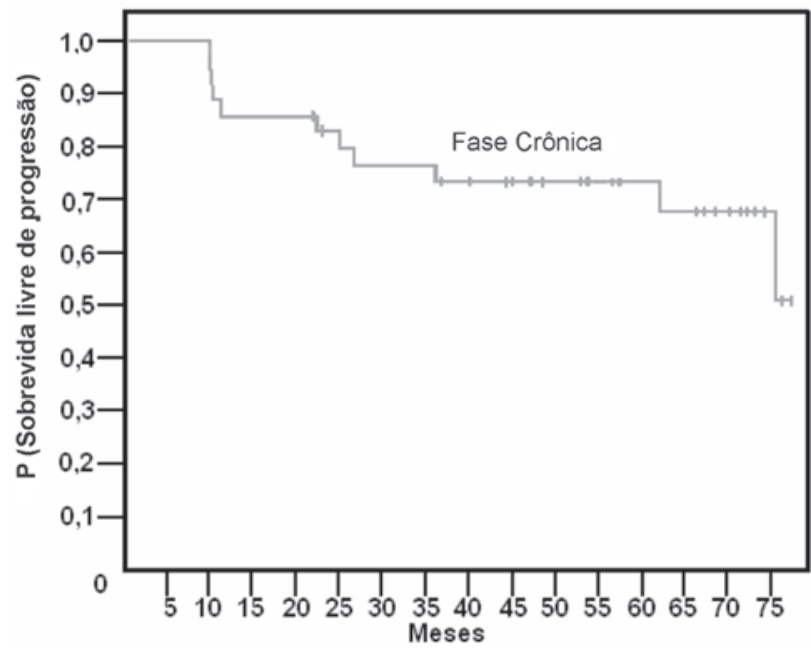

Figura 1. Sobrevida livre de progressão em 35 pacientes com leucemia mieloide crônica em fase crônica

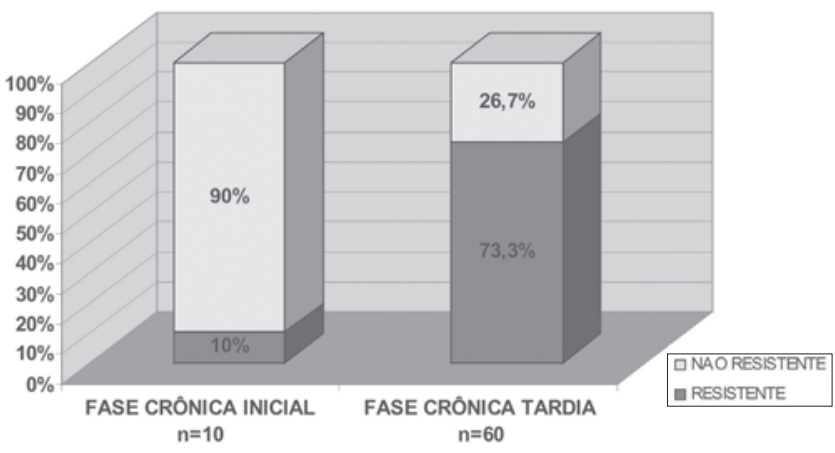

Figura 2. Distribuição de frequência da resistência entre dez pacientes com leucemia mieloide crônica em fase crônica inicial e 60 pacientes em fase crônica tardia

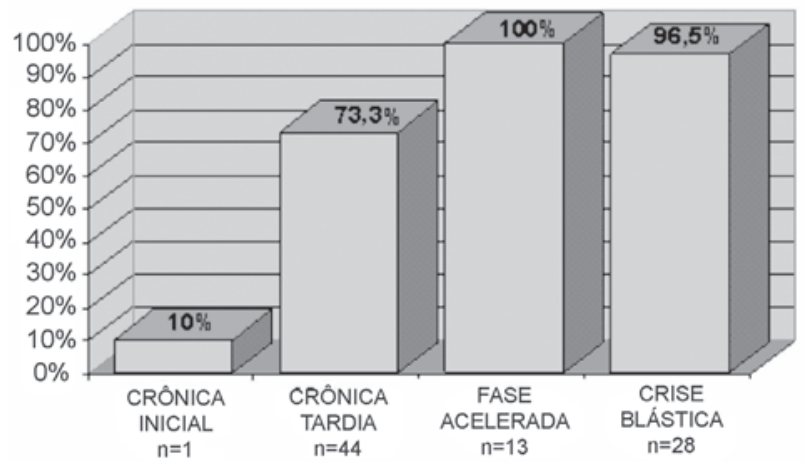

Figura 3. Distribuição de frequência da resistência segundo fase da leucemia mieloide crônica
Na Tabela 6 observa-se que foram identificadas oito mutações diferentes, sendo que em um paciente, em crise blástica, caracterizaram-se duas mutações. Nesta tabela verifica-se a distribuição dos pacientes segundo a fase da doença, com a identificação de apenas um paciente em fase crônica inicial e com mutação. Referente ao tipo de resistência, caracterizaram-se, entre aqueles com mutação, cinco com resistência primária (62,5\%) e três com secundária (37,5\%). Todos sem mutação apresentaram resistência primária.

Houve progressão para fases mais avançadas em cinco casos sendo quatro pacientes com mutação e um sem mutação. Remissão hematológica e citogenética, ao final do estudo, ocorreu em dois pacientes com mutação e dois sem mutação.

Fatores de risco para mutação pontual no domínio quinase $A B L$

Realizada análise univariada entre sete pacientes resistentes em fase crônica com mutação e 13 em fase crônica sem mutação para variáveis clínicas e laboratoriais. Observa-se na Tabela 7 que a presença de blastos no sangue periférico ao diagnóstico apresentou associação estatística significante com a condição de mutação.

\section{Resposta e sobrevida livre de progressão}

Todos os pacientes sem mutação e seis $(35,7 \%)$ com mutação obtiveram resposta hematológica completa. Como observado na Figura 9, não houve diferença para o tempo até obtenção desta resposta, mas, como demonstrado na Figura 10, há uma diferença estatística significante em relação ao tempo para a perda da resposta hematológica completa.

Dois pacientes com mutação e quatro sem obtiveram resposta citogenética completa. Não houve diferença para o tempo até a obtenção dessa resposta, como é observado na Figura 11. Como observado na Figura 12, não houve diferença estatística entre as curvas de sobrevida livre de progressão.

\section{Discussão}

A resistência ao imatinibe, expressa como refratariedade ou recaída, é documentada em todas as fases da doença, principalmente na fase acelerada e crise blástica. Nesse estudo houve demonstração dessa condição, com a constatação de um aumento da frequência da resistência da fase crônica inicial para as fases mais avançadas, ou seja, $10 \%$ a $100 \%$.

Outro aspecto observado foi a baixa frequência da resistência primária hematológica $(1,4 \%)$ na fase crônica, condizente com o encontrado por outros pesquisadores, como $3 \%{ }^{4}$ e $4 \% .^{5}$ Em contraposto, a frequência da resistência citogenética primária - 49,3\% - foi superior ao descrito na literatura, como documentado, por exemplo, no seguimento de 454 pacientes em fase crônica, intolerantes ou resistentes ao IFN- $\alpha$, com um seguimento de 29 meses, onde se caracte- 
Tabela 2. Análise Univariada de variáveis clínicas pré-imatinibe e laboratoriais de 45 pacientes com LMC em fase crônica resistentes e 25 não resistentes (Santa Casa de São Paulo, 2000 a 2005)

\begin{tabular}{|c|c|c|c|}
\hline Variável & Resistentes & Não Resistentes & $\mathrm{p}$ \\
\hline $\begin{array}{l}\text { Sexo } \\
\text { Feminino } \\
\text { Masculino } \\
\text { Total }\end{array}$ & $\begin{array}{l}24(53,3) \\
21(46,7) \\
45(100)\end{array}$ & $\begin{array}{l}12(48) \\
13(52) \\
25(100)\end{array}$ & 0,669 \\
\hline $\begin{array}{l}\text { Hasford } \\
\text { Baixo } \\
\text { Intermédio } \\
\text { Alto } \\
\text { Total }\end{array}$ & $\begin{array}{c}12(36,4) \\
12(36,4) \\
9(27,3) \\
33(100)^{\star}\end{array}$ & $\begin{array}{l}13(59,1) \\
6(27,3) \\
3(13,6) \\
22(100)^{*}\end{array}$ & 0,228 \\
\hline $\begin{array}{l}\text { Sokal } \\
\text { Baixo } \\
\text { Intermédio } \\
\text { Alto } \\
\text { Total }\end{array}$ & $\begin{array}{c}7(21,2) \\
10(30,3) \\
16(48,5) \\
33(100)^{\star}\end{array}$ & $\begin{array}{c}6(28,6) \\
11(52,4) \\
4(19) \\
21(100)^{\star}\end{array}$ & 0,086 \\
\hline $\begin{array}{l}\text { Hemoglobina }(\mathrm{g} / \mathrm{dl}) \\
\qquad \begin{array}{l}<12 \\
>12 \\
\text { Total }\end{array}\end{array}$ & $\begin{array}{l}17(37,8) \\
28(62,2) \\
45(100)\end{array}$ & $\begin{array}{c}5(20) \\
20(80) \\
25(100)\end{array}$ & 0,125 \\
\hline $\begin{array}{l}\text { Leucócitos } \\
\qquad 40 \mathrm{mil} \\
>40 \mathrm{mil} \\
\text { Total }\end{array}$ & $\begin{array}{c}41(91,1) \\
4(8,9) \\
45(100)\end{array}$ & $\begin{array}{c}24(96) \\
1(4) \\
25(100)\end{array}$ & 0,447 \\
\hline $\begin{array}{l}\text { Blastos no sangue periférico } \\
\quad 0 \\
\begin{array}{l}1 \text { e } 2 \\
\geq 3 \\
\text { Total }\end{array}\end{array}$ & $\begin{array}{l}35(77,8) \\
5(11,1) \\
5(11,1) \\
45(100)\end{array}$ & $\begin{array}{c}24(96) \\
0(0) \\
1(4) \\
25(100)\end{array}$ & 0,113 \\
\hline $\begin{array}{l}\text { Blastos na medula óssea } \\
\quad \leq 5 \\
\quad>5 \\
\text { Total }\end{array}$ & $\begin{array}{c}43(95,6) \\
2(4,4) \\
45(100)^{\star}\end{array}$ & $\begin{array}{c}23(95,8) \\
1(4,2) \\
24(100)^{\star}\end{array}$ & 0,957 \\
\hline $\begin{array}{l}\text { Plaquetas }\left(\mathrm{p} / \mathrm{mm}^{3}\right) \\
\quad<450 \mathrm{mil} \\
451 \text { a } 700 \mathrm{mil} \\
>700 \mathrm{mil} \\
\text { Total }\end{array}$ & $\begin{array}{l}28(62,2) \\
6(13,3) \\
11(24,4) \\
45(100)\end{array}$ & $\begin{array}{c}22(88) \\
3(12) \\
0(0) \\
25(100)\end{array}$ & 0,022 \\
\hline $\begin{array}{l}\text { Plaquetas }\left(\mathrm{p} / \mathrm{mm}^{3}{ }^{3}\right. \\
\quad>50 \mathrm{~mL} \\
\leq 50 \mathrm{~mL} \\
\text { Total }\end{array}$ & $\begin{array}{l}26(57,8) \\
19(42,2) \\
45(100)\end{array}$ & $\begin{array}{c}22(88) \\
3(12) \\
25(100)\end{array}$ & 0,009 \\
\hline $\begin{array}{l}\text { Suspensão da medicação } \\
\text { < } 4 \text { semanas } \\
>4 \text { semanas } \\
\text { Total }\end{array}$ & $\begin{array}{l}20(44,4) \\
25(55,6) \\
45(100)\end{array}$ & $\begin{array}{c}14(56) \\
11(44) \\
25(100)\end{array}$ & 0,354 \\
\hline $\begin{array}{l}\text { Mutação no domínio quinase ABL } \\
\text { Não } \\
\text { Sim } \\
\text { Total }\end{array}$ & $\begin{array}{c}13(28,9) \\
7(15,6) \\
20(100)^{\star}\end{array}$ & $\begin{array}{c}1(4) \\
0(0) \\
1(100)^{\star}\end{array}$ & $>0,99$ \\
\hline $\begin{array}{l}\text { Resposta ao IFN- } \alpha \\
\text { Resistência Citogenética } \\
\text { Recidiva Citogenética } \\
\text { Resistência Hematológica } \\
\text { Recidiva Hematológica } \\
\text { Intolerância } \\
\text { Total }\end{array}$ & $\begin{array}{c}14(31,8) \\
1(2,3) \\
14(31,8) \\
7(15,9) \\
8(18,2) \\
44(100)^{\star}\end{array}$ & $\begin{array}{c}9(39,1) \\
3(13,1) \\
2(8,7) \\
2(8,7) \\
7(30,4) \\
23(100)^{*}\end{array}$ & 0,086 \\
\hline
\end{tabular}

* : número de pacientes avaliáveis 
Tabela 3. Análise multivariada de fatores de risco para resistência entre 45 pacientes com LMC em fase crônica e 25 não resistentes (Santa Casa de São Paulo, 2000 a 2005)

\begin{tabular}{ccccc}
\hline Variável & $\begin{array}{c}\text { Estimativa da } \\
\text { da razão } \\
\text { de chances }\end{array}$ & I.C. $95 \%$ & $\begin{array}{c}\text { Valor } \\
\text { de } \mathrm{p}\end{array}$ \\
\hline $\begin{array}{c}\text { Plaquetas ao iniciar } \\
\text { o imatinibe } \\
\left(>450.000 / \mathrm{mm}^{3}\right)\end{array}$ & 4,7 & 1,2 & 19 & 0,029 \\
$\begin{array}{c}\text { Plaquetas durante } \\
\text { a terapia } \\
\left(<50.000 / \mathrm{mm}^{3}\right)\end{array}$ & 5,6 & 1,4 & 22,3 & 0,014 \\
\hline
\end{tabular}

I.C.: Intervalo de confiança.

Tabela 4. Distribuição dos 45 pacientes com leucemia mieloide crônica em fase crônica resistentes e 25 não resistentes segundo resposta hematológica, citogenética e evolução clonal (Santa Casa de São Paulo, 2000 a 2005)

\begin{tabular}{cccc}
\hline Variáveis & & Resistentes $(\%)$ & Não Resistentes (\%) \\
\hline Resposta hematológica & Não & $1(2,2)$ & $0(0)$ \\
completa & Sim & $44(97,8)$ & $25(100$ \\
$p=0,453$ & Total & $45(100)$ & $25(100$ \\
Resposta molecular & Não & $26(57,8)$ & $14(56)$ \\
& RM maior & $0(0)$ & $8(32)$ \\
p $<0,001$ & RM completa & $0(0)$ & $3(12)$ \\
& Total & $26(100)^{\star}$ & $25(100)^{\star}$ \\
Resposta Citogenética & Outras & $23(69,7)$ & $0(0)$ \\
aos 12 meses & Parcial/completa & $10(30,3)$ & $25(100)$ \\
p<0,001 & Total & $33(100)^{\star}$ & $25(100)^{\star}$ \\
Evolução clonal & Não & $34(75,6)$ & $25(100)$ \\
p=0,007 & Sim & $11(24,4)$ & $0(0)$ \\
& Total & $45(100)$ & $25(100)$ \\
\hline
\end{tabular}

$\mathrm{RM}=$ resposta molecular; ${ }^{\star}$ : número de pacientes avaliáveis

Tabela 5. Medidas descritivas para variáveis continuas segundo a condição de resistência para os 45 pacientes com leucemia mieloide crônica em fase crônica resistentes e 25 pacientes não resistentes (Santa Casa de São Paulo, 2000 a 2005)

\begin{tabular}{ccccccccc}
\hline & Resistência & N & Média & $\begin{array}{c}\text { Desvio } \\
\text { padrão }\end{array}$ & Mediana & Mínimo & Máximo & $\begin{array}{c}\text { Valor } \\
\text { de } p\end{array}$ \\
\hline $\begin{array}{c}\text { Idade ao } \\
\text { iniciar imatinibe }\end{array}$ & Sim & 45 & 43,9 & 13,4 & 41,6 & 19,4 & 71,8 & \\
(anos) & Não & 25 & 44,9 & 16,1 & 43,5 & 19,2 & 70,8 & 0,786 \\
TDI & Total & 70 & 44,3 & 14,3 & 42,3 & 19,2 & 71,8 & \\
(meses) & Sim & 45 & 39,1 & 25,7 & 32,7 & 2,7 & 129,5 & 0,043 \\
& Não & 25 & 26,4 & 23,1 & 20,3 & 0,9 & 82,8 & \\
Uso do IFN- $\alpha$ & Total & 70 & 34,6 & 25,4 & 27,7 & 0,9 & 129,5 & \\
(meses) & Sim & 44 & 18,0 & 23,2 & 7,7 & 0,5 & 113,3 & 0,707 \\
& Não & 23 & 20,2 & 23,0 & 12,2 & 0,1 & 79,6 & \\
Tempo até a & Total & 67 & 18,7 & 23,0 & 9,2 & 0,1 & 113,3 & \\
RHC & Sim & 35 & 1,2 & 0,9 & 0,9 & 0,2 & 4,9 & 0,269 \\
(meses) & Não & 11 & 0,9 & 0,4 & 0,9 & 0,4 & 1,5 & \\
\hline
\end{tabular}

$\mathrm{N}=$ Número de pacientes estudados; TDI= Tempo do diagnóstico até início do imatinibe; $\mathrm{RHC}=$ Resposta hematológica completa; IFN $-\alpha=$ Interferon Alfa rizaram 36\% dos pacientes com esse tipo resistência. ${ }^{5}$

Referente à resistência secundária na fase crônica, observou-se uma variação de 17,3\% a 32,4\% em 18 a 60 meses, tivamente. $\mathrm{O}$ encontro dessa frequência crescente é com publicações na literatura., ${ }^{5,67}$ Mas, distinguedos pacientes, classificados como resistentes secundários, recaíram nos primeiros 32 meses. A seguir assemelhou-se ao publicado. $5,6,7$

Um enfoque foi a tentativa de identificar fatores de risco para o desenvolvimento da resistência, uma vez que este reconhecimento pode proporcionar um diagnóstico mais precoce e consequentemente uma otimização da terapia.

A análise entre variáveis clínicas e laboratoriais entre os pacientes resistentes e não resistentes em fase crônica, encontrou uma associação estatística significativa entre o número de plaquetas superior a 450.000/ $\mathrm{mm}^{3}$ no exame pré-imatinibe ou o desenvolvimento de um número inferior a $50.000 / \mathrm{mm}^{3}$ durante o tratamento.

Em relação ao alto número de plaquetas, pode-se citar os pesquisadores Cervantes et al e Sneed et al, os quais, a partir de trabalhos com pacientes em fase crônica, caracterizam a associação desse achado com menor taxa de aquisição de resposta citogenética maior. ${ }^{8,9}$

Quanto à condição de trombocitopenia, é apresentada, por diferentes autores, sua associação com menor obtenção de resposta citogenética maior ${ }^{8,9} \mathrm{e}$, particularmente, pelos pesquisadores Marin et al, o maior risco de progressão. ${ }^{10}$

Uma observação a ser colocada é a respeito da mielotoxidade, a qual pode refletir uma doença mais avançada, onde há menor reserva de células progenitoras normais e com maior probabilidade de progressão e resistência. Mas, outro aspecto ponderável, é que a citotoxicidade pode implicar em redução ou mesmo na suspensão do imatinibe e, consequentemente, a um tratamento insuficiente.

Um comentário a ser destacado diz respeito à repercussão negativa da resistência na evolução dos paci- 


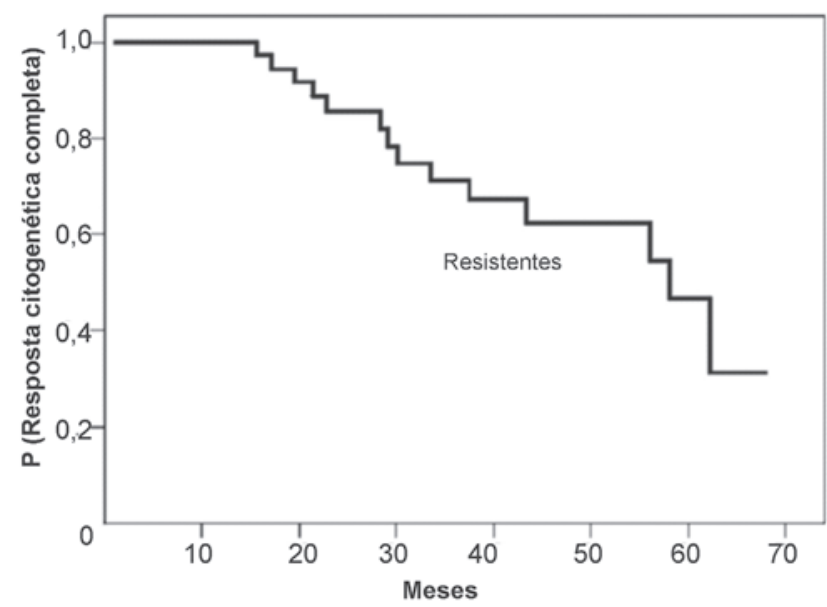

Figura 4. Tempo em meses até a resposta citogenética completa nos pacientes com leucemia mieloide crônica em fase crônica resistentes

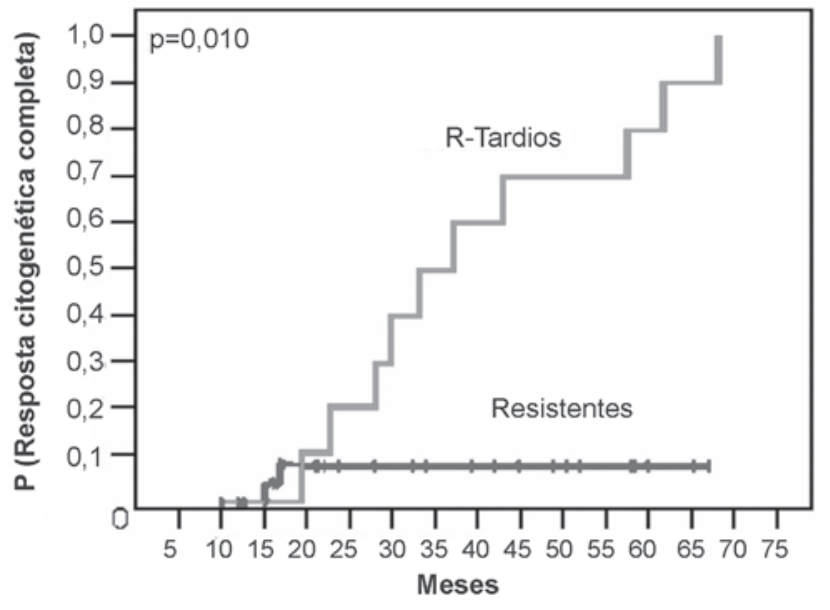

Figura 5. Tempo até a resposta citogenética completa nos pacientes com leucemia mieloide crônica em fase crônica resistentes e pacientes "responsivos tardios"

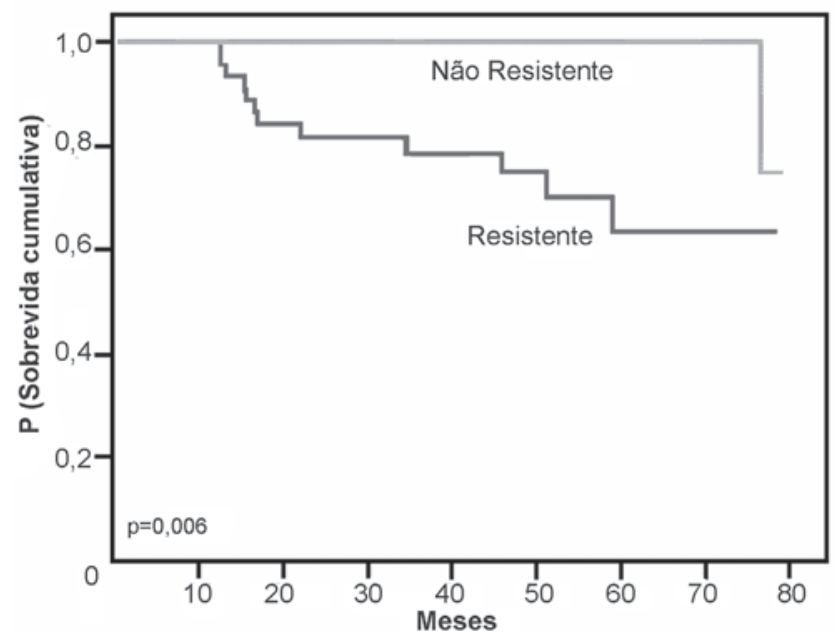

Figura 6. Sobrevida global nos pacientes com leucemia mielóide crônica em fase crônica não resistentes e resistentes

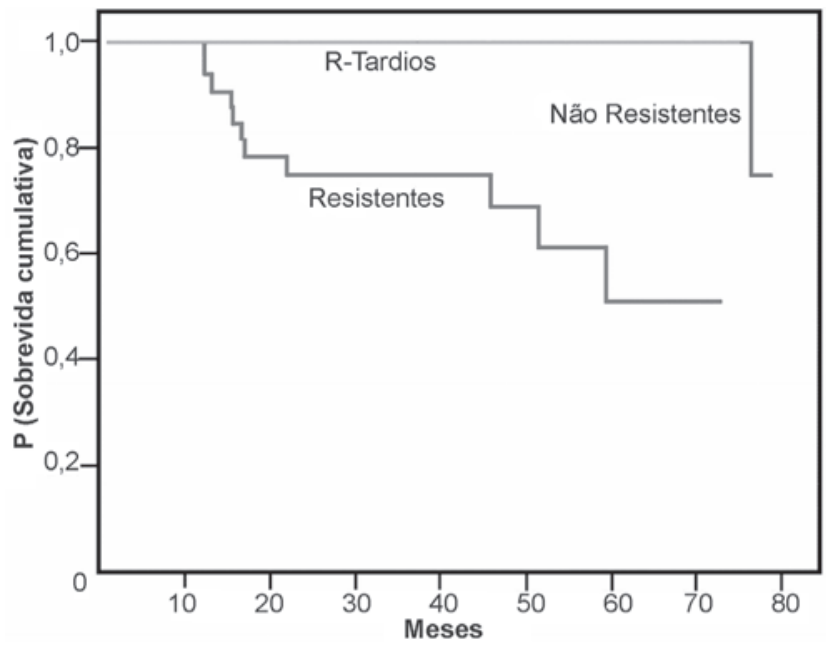

Figura 7. Sobrevida global nos pacientes com leucemia mielóide crônica em fase crônica resistentes, não resistentes e "responsivos tardios"

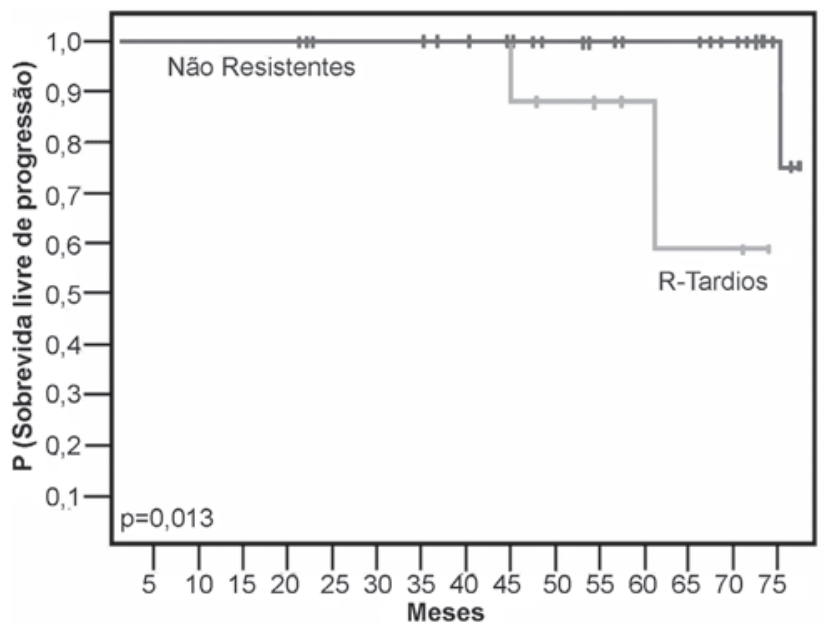

Figura 8. Sobrevida livre de progressão para 25 pacientes com leucemia mielóide crônica em fase crônica não resistentes, e dez resistentes "responsivos tardios"

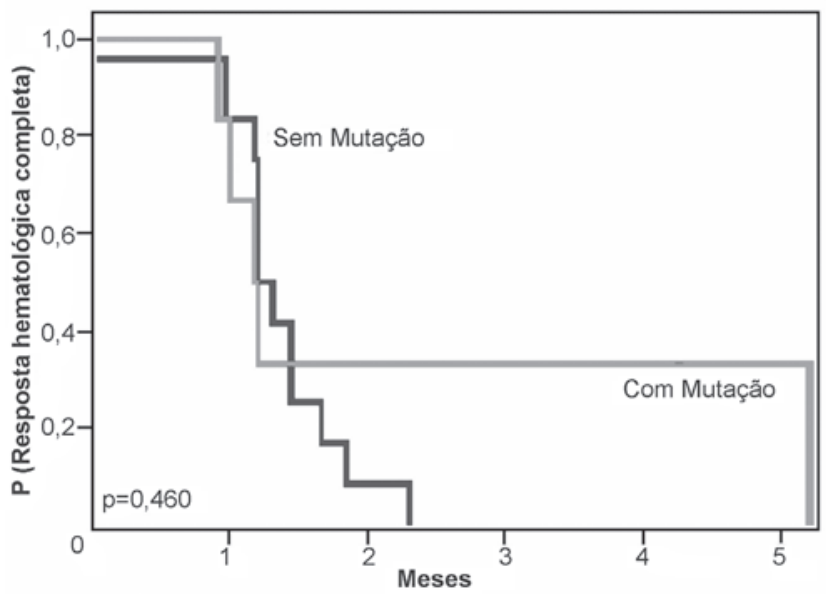

Figura 9. Tempo até obtenção da resposta hematológica completa para pacientes com leucemia mielóide crônica resistentes com mutação pontual no domínio quinase $A B L$ e nos pacientes sem mutação 
Tabela 6. Status e progressão de 8 pacientes com leucemia mieloide crônica e mutação no domínio quinase ABL e 14 sem mutação

\begin{tabular}{|c|c|c|c|c|c|c|c|c|c|}
\hline $\begin{array}{l}\text { Pac. } \\
\mathrm{N}^{\circ} \text {. }\end{array}$ & $\begin{array}{c}\text { TD } \\
\text { Meses }\end{array}$ & $\begin{array}{l}\text { Fase da } \\
\text { doença }\end{array}$ & Mutação & $\begin{array}{c}\text { TM } \\
\text { Meses }\end{array}$ & $\begin{array}{c}\text { Status } \\
\text { Mutação }\end{array}$ & $\mathrm{R}$ & $\begin{array}{l}\mathrm{FA} / \\
\mathrm{CBM}\end{array}$ & $\begin{array}{l}\text { Status } \\
\text { Final }\end{array}$ & $\begin{array}{c}\text { TS } \\
\text { Meses }\end{array}$ \\
\hline 1 & 35 & FCT & $\begin{array}{c}\text { Dupla } \\
\text { População/ } \\
\text { Q252L }\end{array}$ & 18 & RH/RC Não & HS & FA & $\begin{array}{c}\text { Fim } \\
\text { seguimento }\end{array}$ & 17,5 \\
\hline 2 & 36,3 & FCT & $\begin{array}{l}\text { Dupla } \\
\text { População/ } \\
\text { Q252L }\end{array}$ & 59 & $\begin{array}{l}\text { RH Sim /RC } \\
\text { Não }\end{array}$ & $\mathrm{CP}$ & - & $\begin{array}{c}\mathrm{RH} \mathrm{e} \\
\mathrm{RC} \mathrm{Sim}\end{array}$ & 68,7 \\
\hline 3 & 62,4 & CBM & $\begin{array}{l}\text { L248V/ } \\
\text { F486S }\end{array}$ & 45 & $\begin{array}{l}\text { RH/RC Não } \\
\text { RH Sim /RC }\end{array}$ & $\mathrm{CP}$ & CBM & $\begin{array}{l}\text { Fim } \\
\text { seguimento } \\
\text { RH Sim }\end{array}$ & 37 \\
\hline 4 & 2,7 & $\mathrm{FCl}$ & T315I & 32 & Não & CS & - & $\begin{array}{l}\text { RC Não } \\
\text { Fim }\end{array}$ & 41,2 \\
\hline 5 & 53 & FCT & S348L & 63 & RH/RC Não & HS & FA & $\begin{array}{l}\text { seguimento } \\
\text { Saída }\end{array}$ & 73 \\
\hline 6 & 47,4 & FCT & E450G & 54 & $\begin{array}{l}\text { RH/RC Não } \\
\text { RH Sim /RC }\end{array}$ & $\mathrm{CP}$ & - & $\begin{array}{l}\text { Estudo } \\
\text { Saída }\end{array}$ & 54,5 \\
\hline 7 & 48,7 & FCT & M351T & 39 & Não & $\mathrm{HP}$ & FA & $\begin{array}{l}\text { Estudo } \\
\mathrm{RH} \mathrm{e}\end{array}$ & 48,1 \\
\hline 8 & 21,4 & FCT & F359V & 28 & $\begin{array}{l}\text { RH e RC Sim } \\
\text { RH Sim /RC }\end{array}$ & $\mathrm{CP}$ & - & $\begin{array}{l}\text { RC Sim } \\
\text { RH Sim / }\end{array}$ & 30,8 \\
\hline 9 & 21,1 & FCT & - & 19 & $\begin{array}{l}\text { Não } \\
\text { RH Sim /RC }\end{array}$ & $\mathrm{CP}$ & - & $\begin{array}{l}\text { RC Não } \\
\text { Saída }\end{array}$ & 28,5 \\
\hline 10 & 17,5 & FCT & - & 13 & $\begin{array}{l}\text { Não } \\
\text { RH Sim /RC }\end{array}$ & $\mathrm{CP}$ & - & $\begin{array}{l}\text { Estudo } \\
\text { Saída }\end{array}$ & 12,2 \\
\hline 11 & 18,1 & FCT & - & 26 & $\begin{array}{l}\text { Não } \\
\text { RH Sim /RC }\end{array}$ & $\mathrm{CP}$ & - & $\begin{array}{l}\text { Estudo } \\
\text { RH Sim }\end{array}$ & 22,2 \\
\hline 12 & 60,8 & FCT & - & 64 & Não & $\mathrm{CP}$ & - & $\begin{array}{l}\text { RC Não } \\
\text { Saída }\end{array}$ & 63,2 \\
\hline 13 & 87,2 & FCT & - & 45 & RH/RC Não & $\mathrm{CP}$ & - & Estudo & 44,8 \\
\hline 14 & 27,4 & FCT & - & 13 & $\begin{array}{l}\text { RH Sim /RC } \\
\text { Não }\end{array}$ & $\mathrm{CP}$ & - & $\begin{array}{l}\text { RH Sim / } \\
\text { RC Não }\end{array}$ & 24,1 \\
\hline 15 & 25,1 & FCT & - & 34 & $\begin{array}{l}\text { RH Sim /RC } \\
\text { Não } \\
\text { RH Sim /RC }\end{array}$ & $\mathrm{CP}$ & - & $\begin{array}{l}\text { RH e } \\
\text { RC Sim } \\
\text { Saída }\end{array}$ & 43,7 \\
\hline 16 & 32,7 & FCT & - & 53 & Não & $\mathrm{CP}$ & - & $\begin{array}{c}\text { Estudo } \\
\text { RH/ }\end{array}$ & 53,8 \\
\hline 17 & 47,5 & FCT & - & 26 & $\begin{array}{l}\mathrm{RH} / \mathrm{RC} \text { Não } \\
\mathrm{RH} \operatorname{Sim} / \mathrm{RC}\end{array}$ & $\mathrm{CP}$ & - & $\begin{array}{l}\text { RC Não } \\
\text { RH Sim / }\end{array}$ & $\begin{array}{l}35,4 \\
37,5\end{array}$ \\
\hline 18 & 24,2 & FCT & - & 30 & Não & $\mathrm{CP}$ & - & RC Não & \\
\hline 19 & 65,6 & FCT & - & 53 & $\begin{array}{l}\text { RH Sim /RC } \\
\text { Não }\end{array}$ & $\mathrm{CP}$ & - & $\begin{array}{l}\text { RH Sim / } \\
\text { RC Não }\end{array}$ & 54,5 \\
\hline 20 & 15 & FCT & - & 36 & $\begin{array}{l}\text { RH Sim /RC } \\
\text { Não }\end{array}$ & $\mathrm{CP}$ & - & $\begin{array}{l}\text { RH Sim / } \\
\text { RC Não } \\
\text { RH e }\end{array}$ & 37,9 \\
\hline 21 & 14,7 & FCT & - & 57 & RH e RC Sim & $\mathrm{CP}$ & - & $\begin{array}{l}\text { RCC Sim } \\
\text { Óbito pela }\end{array}$ & 66,9 \\
\hline 22 & 92 & FA & - & $60 / 61$ & RH/RC Não & $\mathrm{CP}$ & CBM & doença & 50,1 \\
\hline
\end{tabular}

Abreviaturas: $P$ ac. $=$ Pacientes, $R=$ resistência, $T D=T e m p o$ de diagnóstico; $T M=T e m p o$ da Mutação; FCT=Fase Crônica Tardia; $\mathrm{FCl}=$ Fase Crônica Inicial; $\mathrm{CBM}=$ Crise Blástica Mielóide; FA = Fase Acelerada; RH = Remissão Hematológica; RC = Remissão Citogenética; $\mathrm{ND}=$ Não Disponível; $\mathrm{CP}=$ Citogenética Primária; $\mathrm{CS}=$ Citogenética Secundária HP= Hematológica Primária; HS= Hematológica Secundária; RTQ-PCR\% = sem queda=100\%; queda de 1 Log=10\%; queda de 2 Log= 1\%; queda de 3 Log=0,1\%; queda de $4 \mathrm{Log}=0,01 \%$.

entes com desenvolvimento dessa condição, o que pode ser evidenciado. Nesse trabalho, por exemplo, com a avaliação da sobrevida global, a qual foi significantemente menor nos resistentes em relação aos não resistentes, ou seja 73,8 e 57,5 meses respectivamente.
Entre os 45 pacientes resistentes em fase crônica, destacaram-se dez pacientes, cuja peculiaridade foi a aquisição da resposta citogenética completa, após 12 meses de terapêutica. A avaliação desses pacientes em relação aos não resistentes mostrou que obtiveram e mantiveram a resposta 


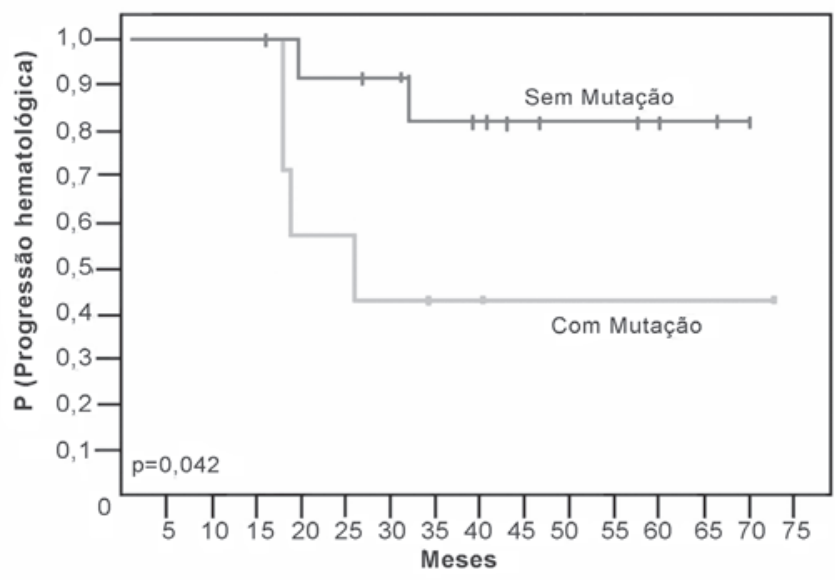

Figura 10. Tempo até a perda da resposta hematológica completa em meses para 13 pacientes com leucemia mieloide crônica em fase crônica resistentes sem mutação pontual no domínio quinase $A B L$ e para sete pacientes com mutação

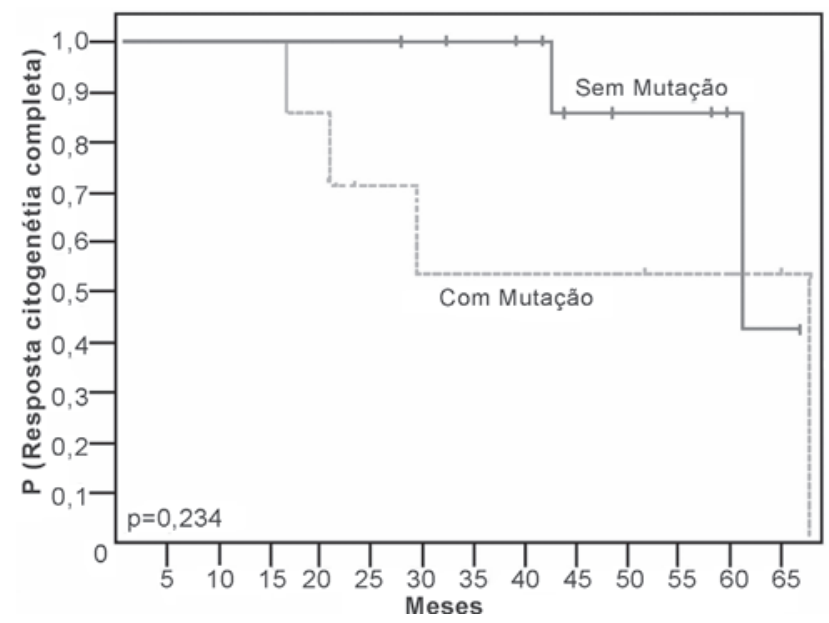

Figura 11. Sobrevida livre de progressão em 13 pacientes com leucemia mielóide crônica em fase crônica resistentes sem mutação pontual no domínio quinase $A B L$ e nos sete pacientes com mutação pontual

hematológica completa como esses. Em relação à sobrevida global foi semelhante até os 70 meses e a sobrevida livre de progressão até os 40 meses.

Segundo os pesquisadores Iacobucci et al, pacientes que no período de 12 meses apresentam uma boa resposta citogenética, a resposta completa pode requerer mais de um ano e o seguimento mostra uma evolução favorável, como o observado nos dez pacientes do presente estudo. ${ }^{11}$

Uma suposição seria que a heterogeneidade do perfil gênico da doença e do paciente permitiria diferentes comportamentos de resposta, possibilitando desde aquele paciente que mantém o potencial de resposta, mesmo que tardiamente, até aquele que desenvolve refratariedade ou recidiva.

Em termos da frequência da resistência primária hematológica observada na fase acelerada e crise blástica, 45,1\% e

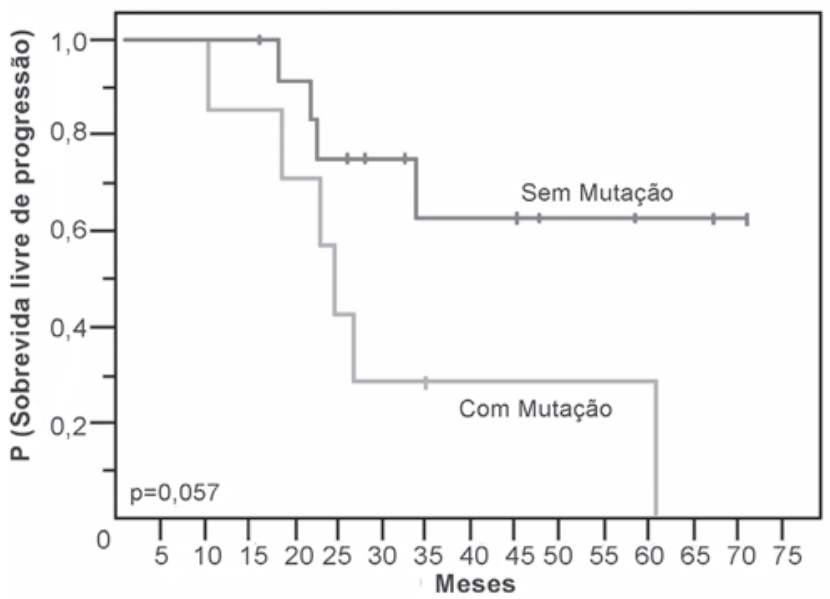

Figura 12. Tempo até obtenção da resposta citogenética completa para 13 pacientes com leucemia mieloide crônica resistentes com mutação pontual no domínio quinase $A B L$ e nos sete pacientes sem mutação (Santa Casa de São Paulo, 2000 a 2005).

69\% respectivamente, se assemelham às da literatura ${ }^{12,13} \mathrm{e}$ refletem a gravidade da doença e a limitação da eficiência do inibidor quinase na fases mais avançadas.

Quanto aos mecanismos responsáveis pela resistência, nesse estudo destacou-se a identificação de mutação pontuais no domínio quinase ABL. Em 22 casos estudados, caracterizou-se em 36,4\% dos pacientes. Entre as mutações encontradas, evidenciaram-se por serem descritos frequentemente em recaída: Na região P-loop:Q-252L; no sítio de ligação: T315I e no domínio catalítico M351T e F359V. ${ }^{14}$ Destacou-se a mutação T315I, pelo seu caráter de alta insensibilidade, inclusive para inibidores de tirosina-quinase de segunda geração.

Um objetivo desse estudo foi a definição de fatores de risco para o desenvolvimento de mutação, a partir da análise de variáveis clínicas e laboratoriais entre pacientes com e sem mutação em fase crônica. Encontrou-se associação estatística significante apenas para o número de blastos no sangue periférico ao diagnóstico.

Embasa a importância desse achado, um trabalho desenvolvido pelos pesquisadores Branford et al, em pacientes em fase crônica, onde uma estratificação de risco é proposta segundo a porcentagem de blastos no sangue periférico e/ou o intervalo entre o diagnóstico e o início do imatinibe. ${ }^{15}$

Outro dado a se destacar é a ausência de uma diferença estatística significante para a sobrevida livre de progressão entre os grupos com e sem mutação, embora seja descrita a maior probabilidade de progressão para a fase acelerada ou crise blástica e menor sobrevida nos pacientes com mutação. ${ }^{16,17}$

Deve se destacar que, independente da ausência da diferença da sobrevida livre de progressão, a evolução para fase acelerada ou crise blástica ocorreu apenas nos pacientes com mutação. 
Tabela 7: Análise univariada de característica clínicas e laboratoriais para mutação entre 13 pacientes em fase crônica sem mutação no domínio quinase $\mathrm{ABL}$ e sete com mutação

\begin{tabular}{|c|c|c|c|}
\hline & Sem Mutação & Com Mutação & $\mathrm{p}$ \\
\hline Idade ao iniciar o imatinibe & 42,5 & 42,3 & 0,877 \\
\hline $\begin{array}{l}\text { Sexo } \\
\text { Masculino } \\
\text { Feminino } \\
\text { Total }\end{array}$ & $\begin{array}{l}5(38,5) \\
8(61,5) \\
13(100)\end{array}$ & $\begin{array}{l}4(57,1) \\
3(42,9) \\
7(100)\end{array}$ & 0,642 \\
\hline $\begin{array}{l}\text { Tempo do diagnóstico até iniciar } \\
\text { o imatinibe (meses) }\end{array}$ & 34,9 & 35,1 & 0,643 \\
\hline $\begin{array}{l}\text { Hasford } \\
\text { Baixo } \\
\text { Intermediário } \\
\text { Alto } \\
\text { Total }\end{array}$ & $\begin{array}{c}6(54,5) \\
4(36,4) \\
1(9,1) \\
11(100)^{\star}\end{array}$ & $\begin{array}{c}0(0,0) \\
2(40) \\
3(60) \\
5(100)^{\star}\end{array}$ & 0,059 \\
\hline $\begin{array}{l}\text { Sokal } \\
\text { Baixo } \\
\text { Intermediário } \\
\text { Alto } \\
\text { Total }\end{array}$ & $\begin{array}{c}4(36,4) \\
3(27,2) \\
4(36,4) \\
11(100)^{\star}\end{array}$ & $\begin{array}{c}1(20) \\
0(0) \\
4(80) \\
5(100)^{\star}\end{array}$ & 0,385 \\
\hline $\begin{array}{l}\text { Blastos no Sangue Periférico (\%) } \\
\text { ao diagnóstico } \\
\quad 0 \\
\begin{array}{l}1 \text { e } 2 \\
\geq 3 \\
\text { Total }\end{array}\end{array}$ & $\begin{array}{c}6(54,5) \\
5(45,5) \\
0(0) \\
11(100)^{\star}\end{array}$ & $\begin{array}{c}0(0) \\
4(66,7) \\
2(33,3) \\
6(100)^{\star}\end{array}$ & 0,025 \\
\hline $\begin{array}{l}\text { Evolução clonal } \\
\text { Não } \\
\text { Sim } \\
\text { Total }\end{array}$ & $\begin{array}{l}9(69,2) \\
4(30,8) \\
13(100)\end{array}$ & $\begin{array}{c}5(71,4) \\
2(28,6) \\
7(100)\end{array}$ & 0,99 \\
\hline
\end{tabular}

* : número de pacientes avaliáveis

Um outro aspecto a ser comentado é a respeito da maior frequência das mutações em pacientes com resistência secundária em relação à primária, segundo vários autores..$^{18,3}$ Porém, no presente trabalho, 62,5\% dos pacientes com mutação apresentaram resistência primária, o que pode refletir a relevância desse mecanismo nesse tipo de resistência. Embasa esse achado a publicação de Soverini et al (2005), onde, na análise de 40 pacientes com leucemia mieloide crônica em fase crônica tardia e resistência citogenética primaária, identificaram-se 19 pacientes (48\%) com mutação pontual.

Com esse estudo é possível denotar que, embora o mesilato de imatinibe modifique a história natural da doença, a condição de resistência ainda é um desafio, apresentandose em uma proporção considerável de pacientes, principalmente nas fases avançadas da doença. Com essa premissa, torna-se essencial o conhecimento de fatores que possam identificar o risco do desenvolvimento de resistência e com isso orientar um monitoramento mais rigoroso, um diagnóstico mais precoce e um direcionamento terapêutico. Igualmente importante é a identificação e o diagnóstico precoce da mutação, cujo papel no fenótipo da resistência deve ser interpretado no contexto clínico.

\section{Conclusões}

Os pacientes com leucemia mieloide crônica em fase crônica tardia, em relação aos da fase crônica inicial, tiveram mais frequentemente resistência primária e secundária ao imatinibe. Caracterizou-se como fatores de risco para o desenvolvimento de resistência na fase crônica um número de plaquetas superior a $450.000 / \mathrm{mm}^{3}$, no exame hematimétrico pré-imatinibe ou para um número inferior a $50.000 / \mathrm{mm}^{3}$ durante o tratamento. Embora as taxas de respostas hematológica completa e o tempo mediano para sua aquisição tenham sido semelhantes entre os pacientes na fase crônica com e sem resistência, houve diferença estatística significante para a resposta molecular, uma vez que nenhum resistente apresentou resposta maior ou completa.

Identificaram-se entre os resistentes em fase crônica pacientes com resposta citogenética completa após 12 meses de terapêutica (responsivos tardios), os quais se destacaram por apresentar respostas hematológica e citogenética semelhantes aos não resistentes. Esses pacientes apresentaram sobrevida global semelhante aos não resistentes até os 70 meses de seguimento, o que diferiu dos demais resistentes, cuja sobrevida foi significantemente menor em relação ao não resistente. A sobrevida livre de progressão dos responsivos tardios foi semelhante até os 40 meses em relação à sobrevida dos pacientes não resistentes.

Houve identificação de mutação pontual no domínio quinase $\mathrm{ABL}$ em 36,4\% de 22 pacientes resistentes estudados.

Entre os pacientes em fase crônica com e sem mutação não houve diferença nas taxas das respostas hematológica e citogenética, mas apenas em relação à sobrevida livre de progressão hematológica, superior naqueles sem mutação.

Não existiu diferença para a sobrevida livre de progressão entre esses subgrupos.

Observou-se uma associação significativa entre o número de blastos no sangue periférico ao diagnóstico e a presença de mutação pontual.

\footnotetext{
Abstract

Imatinib mesylate, as target therapy, is highly efficient in chronic myelogenous leukemia. A challenge is primary and secondary resistance, particularly in the advanced phases of the disease. In secondary resistance, point mutations in the ABL dominion are the most common mechanism. From October 2000 to December 2005, 112 patients were investigated in the Hematology and Hemotherapy Service of Santa Casa of Sao Paulo. The aim was to characterize the profile of resistance and study the presence of the
} 
mutation. The majority of resistant patients were in the most advanced phases of the disease. Risk factors for resistance in the chronic phase were a platelet count higher than 450,000/mm3 before imatinib treatment or less than 50,000/mm3 during treatment. The total hematological response rate and the time to achieve this were similar between resistant and non-resistant patients. Lower overall survival was observed with resistance. It was notable that ten resistant patients had complete cytogenetic responses after 12 months (late responses) with both hematological and cytogenetic response rates similar to non-resistant patients (100\%). Survival free from progression was similar up to 40 months and the overall survival rate was comparable up to 70 months. The overall survival and response to treatment were better than for the other resistant patients. In respect to the investigation of mutations, 22 resistant patients were investigated with eight presenting with the mutation (36.4\%) The presence of blast cells in the peripheral blood at diagnosis of patients in the chronic phase was characterized as a higher risk factor for this mutation. Rev. Bras. Hematol. Hemoter. 2009;31(3):166-177

Key words: Chronic myelogenous leukemia; tyrosine-kinase inhibitor; imatinib mesylate; resistance; mutation.

\section{Referências Bibliográficas}

1.Deininger M, Buchdunger E, Druker BJ. The development of imatinib as a therapeutic agent for chronic myeloid leukemia. Blood. 2005;105(7):2640-53.

2. Hochhaus A, Erben P, Ernst T, Mueller MC. Resistance to targeted therapy in chronic myelogenous leukemia. Semin Hematol. 2007; 44(1 Suppl 1):S15-24.

3. Shah NP. Loss of response to imatinib: mechanisms and management. Hematology Am Soc Hematol Educ Program. 2005:183-7.

4. Druker BJ. Tendências atuais no tratamento e no monitoramento de pacientes com leucemia mieloide crônica. [São Paulo]: BristolMyers Squibb; s.d. 2006;19p.

5. Kantarjian HM, Schiffer CA, Sawyers CL, Hochhaus A, Guilhot F, Niederwieser DW, et al. Imatinib maintains favorable long-term outcomes in chronic-phase myeloid leukemia (CML) for patients failing interferon-alfa (IFN)-follow-up of a phase II study. [Abstract 3368]. Blood. 2003;102:3368.

6. Kantarjian H, Sawyers C, Hochhaus A, Guilhot F, Schiffer C, Gambacorti-Passerini C, et al. Hematologic and cytogenetic responses to imatinib mesylate in chronic myelogenous leukemia. N Engl J Med. 2002;346(9):645-52.

7. Kantarjian HM, Sawyers C, Hochhaus A, Schiffer AC, Guilhot F, Niederwiser DW, et al. Six year follow-up results of a phase II study of imatinib in late chronic phase (L-CP) chronic myeloid leukemia (CML) post interferon-A (IFN) refractoriness/ intolerance. [Abstract 428]. Blood. 2006; 108:428.

8. Cervantes F, Hernández-Boluda JC, Steegmann JL, Conde E, AlvarezLarrán A, López-Jiménez J, et al. Imatinib mesylate therapy of chronic phase chronic myeloid leukemia resistant or intolerant to interferon: results and prognostic factors for response and progression-free survival in 150 patients. Haematologica. 2003;88(10):1117-22.

9. Sneed TB, Kantarjian HM, Talpaz M, O'Brien S, Rios MB, Bekele $\mathrm{BN}$, et al. The significance of myelosuppression during therapy with imatinib mesylate in patients with chronic myelogenous leukemia in chronic phase. Cancer. 2004;100(1):116-21.
10. Marin D, Kaeda J, Szydlo R, Saunders S, Fleming A, Howard J, et al. Monitoring patients in complete cytogenetic remission after treatment of CML in chronic phase with imatinib: patterns of residual leukaemia and prognostic factors for cytogenetic relapse. Leukemia. 2005;19(4):507-12.

11. Iacobucci I, Rosti G, Amabile M, Poerio A, Soverini S, Cilloni D, et al. Comparison between patients with Philadelphia-positive chronic phase chronic myeloid leukemia who obtained a complete cytogenetic response within 1 year of imatinib therapy and those who achieved such a response after 12 months of treatment. J Clin Oncol. 2006;24(3):454-9.

12. Talpaz M, Goldman JM, Sawyers CL, Hochhaus A, Silver RT, Smith DB, et al. High dose imatinib (STI1571, Gleevec) provides durable long-term outcomes for patients (Pts) with chronic myeloid leukemia (CML) in accelerated phase (AP) or myeloid blast crisis (BC): followup of the phase II studies. [abstract 3369]. Blood. 2003;102.

13. Funke VAM, Medeiros CR, Lima DH, Setúbal DC, Bittencourt MA, Bonfim CM, et al. Therapy of chronic myeloid leukemia with imatinib mesylate in Brasil: A study of 98 cases. Rev. Bras. Hematol. Hemoter. 2005;27(3):159-165.

14. Melo JV, Hughes TP, Apperley JF. Chronic myeloid leukemia. Hematology Am Soc Hematol Educ Program. 2003:132-52.

15. Branford S, Rudzki Z, Lynch K, Hugles T. Pre-imatinib factors can be used to define risk of BCR-ABL mutations for patients with CML in chronic phase and identify a minority who should have regular mutation screening. [abstract 1079] Blood. 2005; 106:46.

16. Branford S, Rudzki Z, Walsh S, Parkinson I, Grigg A, Szer J, et al. Detection of BCR-ABL mutations in patients with CML treated with imatinib is virtually always accompanied by clinical resistance, and mutations in the ATP phosphate-binding loop (P-loop) are associated with a poor prognosis. Blood. 2003;102(1):276-83.

17. Soverini S, Martinelli G, Rosti G, Bassi S, Amabile M, Poerio A, et al. ABL mutations in late chronic phase chronic myeloid leukemia patients with up-front cytogenetic resistance to imatinib are associated with a greater likelihood of progression to blast crisis and shorter survival: a study by the GIMEMA Working Party on Chronic Myeloid Leukemia. J Clin Oncol. 2005;23(18):4100-9.

18. Hochhaus A, La Rosée P. Imatinib therapy in chronic myelogenous leukemia: strategies to avoid and overcome resistance. Leukemia. 2004;18(8):1321-31.

Avaliação: Editor e dois revisores externos

Conflitos de interesse: sem conflito de interesse

Recebido: 03/11/2007

Aceito após modificações: 16/04/2009 